\title{
Interaction of RECQ4 and MCM10 is important for efficient DNA replication origin firing in human cells
}

\author{
Maciej Kliszczak ${ }^{1}$, Hana Sedlackova², Ganesha P. Pitchai ${ }^{3}$, Werner W. Streicher ${ }^{3,4}$, \\ Lumir Krejci ${ }^{2}$ and Ian D. Hickson ${ }^{1}$ \\ ${ }^{1}$ Center for Chromosome Stability and Center for Healthy Aging, Department of Cellular and Molecular Medicine, University \\ of Copenhagen, Copenhagen N, Denmark \\ ${ }^{2}$ National Centre for Biomolecular Research and Department of Biology, Masaryk University, and St Anne's University \\ Hospital, Brno, Czech Republic \\ ${ }^{3}$ Novo Nordisk Foundation Centre for Protein Research, Faculty of Health and Medical Sciences, University of Copenhagen, \\ Copenhagen N, Denmark \\ ${ }^{4}$ Present address: Novozymes A/S, 2880 Bagsvaerd, Denmark \\ Correspondence to: Ian D. Hickson, email: iandh@sund.ku.dk
}

Keywords: DNA replication, RecQ helicases, minichromosome maintenance proteins, Chromosome Section

Received: November 09, $2015 \quad$ Accepted: November 10,2015 Published: November 17, 2015

\section{ABSTRACT}

DNA replication is a highly coordinated process that is initiated at multiple replication origins in eukaryotes. These origins are bound by the origin recognition complex (ORC), which subsequently recruits the $\mathrm{Mcm}$ 2-7 replicative helicase in a Cdt1/Cdc6-dependent manner. In budding yeast, two essential replication factors, SId 2 and Mcm 10, are then important for the activation of replication origins. In humans, the putative SId2 homolog, RECQ4, interacts with MCM10. Here, we have identified two mutants of human RECQ4 that are deficient in binding to MCM10. We show that these RECQ4 variants are able to complement the lethality of an avian cell RECQ4 deletion mutant, indicating that the essential function of RECQ4 in vertebrates is unlikely to require binding to MCM10. Nevertheless, we show that the RECQ4MCM10 interaction is important for efficient replication origin firing.

\section{INTRODUCTION}

The control of the initiation of DNA replication is important for the timely and faithful duplication of the genome. DNA replication initiation occurs in two defined steps, which are conserved amongst vertebrate species. In the first step, conducted prior to S-phase, the origin recognition complex (ORC) binds to specific replication origins. With the exception of certain lower eukaryotes, these origins do not have a well-defined DNA sequence [1]. It is possible that other structural features of the DNA define an origin; for example, specific chromatin marks, or the presence of DNA secondary structures in the proximity of the replication origin. Indeed, the presence of G-quadruplexes has recently been proposed to play an important role in the initiation of DNA replication in chicken cells $[2,3]$. The origin-bound ORC directs the recruitment of Cdc6 and Cdt1, which subsequently allows loading of the heterohexameric replicative helicase comprising the Mcm2-7 proteins $[4,5]$. In the second step, origin activation depends on the Cdc7-Dbf4 (DDK) and
S-phase cyclin dependent kinases (S-CDK) (reviewed in [6]). In budding yeast, DDK phosphorylates the Mcm2-7 helicase in Sld3-dependent manner (TRESLIN in humans) leading to its activation through recruitment of Cdc45 [7]. Following this, S-CDK phosphorylates Sld2 (RECQ4 in humans) and Sld3, facilitating the binding of the BRCT domain-containing protein, Dpb11 (TOPBP1 in humans) and recruitment of the GINS complex to the already assembled origin-protein complex [8, 9]. Similarly, phosphorylation of TRESLIN is important for interaction with TOPBP1 and for normal S-phase progression in human and Xenopus systems [10, 11]. Activation of the replicative helicase occurs through the formation of the CMG complex comprising the Cdc45-Mcm2-7-GINS, which possesses robust DNA unwinding activity $[12,13]$. This pre-initiation complex then recruits $\mathrm{Mcm} 10$ which serves as a chaparone for Polymerases $\alpha$ and $\delta$ leading to the formation of active replication forks and subsequently to genome duplication (reviewed in [14]).

RECQ4, together with RECQ1, BLM, WRN and RECQ5, belongs to the RecQ helicase family required 
for multiple aspects of DNA metabolism. The N-terminal region of RECQ4, not associated with the conventional RecQ helicase core domain, is the only region to share homology with Sld2 [15-17]. Mutations of human RECQ4 have been linked to three distinct clinical syndromes: Rothmund-Thomson type II, RAPADILINO and Baller-Gerold. These disorders share some overlapping phenotypes, including radial ray defects, facial dysmorphia and a predisposition to the development of cancer, especially osteosarcoma. In addition, RAPADILINO and Baller-Gerold individuals show skeletal defects, such as a malformed patella and craniosynostosis, respectively (reviewed in [18]). Interestingly, most of the mutations found in affected individuals occur outside of the Sld2like N-terminal domain of the protein, but instead usually affect the helicase and $\mathrm{C}$-terminal domain containing the RQC motif of RECQ4. This suggests that a lack of DNA unwinding mediated by RECQ4 might be important in the etiology of these diseases ([19, 20] and reviewed in ([18]).

RECQ4 and its homologs appear to play roles in both DNA repair and DNA replication [15, 16, 20-36]. The N-terminal Sld2-like domain is apparently the only region of RECQ4 that is required for DNA replication in vertebrates $[15,16,31,35,36]$. This domain contains a disordered region required for interaction with DNA substrates that possibly form at origins of replication, including G-quadruplexes and Y-DNA [37, 38]. Moreover, the first 54 amino acids of RECQ4 fold into a homeodomain-like DNA binding site [39]. RECQ4 binds to origins of DNA replication at the G1/S-phase boundary, and its depletion leads to significant reduction in the frequency of origin firing in human cells [35]. RECQ4 depletion does not affect replication elongation, in line with what is known about Sld2 in budding yeast [35, 40]. Human RECQ4 interacts physically with MCM10 and CTF4, and is required for the association of these proteins with replication origins. In turn, MCM10 is required for RECQ4 localisation to origins [41]. Moreover MCM10 bridges RECQ4 association with the MCM2-7 helicase, suggesting that the MCM10-RECQ4 complex might be critical for origin activation [32].

Yeast Mcm10 was first identified in genetic screens for mutants defective in DNA replication and mini-chromosome maintenance $[42,43]$. Mcm10 is an evolutionary conserved factor with a centrally located DNA binding zinc finger motif that is necessary for cell viability in budding yeast [44]. In vertebrates, MCM10 physically interacts with the MCM2-7 helicase and TOPBP1, and is required for the loading of POL $\alpha$, POL $\delta$ and RPA to replication origins, as well as for stabilization of POL $\alpha$ at active replication forks [25, 45-48]. Budding yeast $\mathrm{Mcm} 10$ is recruited to the chromatin after formation of the pre-initiation complex in a CDK-dependent step and this recruitment requires prior loading of $\mathrm{Cdc} 45$, Sld2, Sld3, GINS and Dpb11, suggesting that Mcm10 functions in the latter stages of origin activation [47, 49].
In order to define the role of the interaction between RECQ4 and MCM10, we identified the MCM10 interaction interface on RECQ4. We generated two RECQ4 mutants deficient in MCM10 binding, and have analyzed the consequences of the loss of the RECQ4MCM10 interaction on cell proliferation, cell cycle progression and replication origin firing. We found that RECQ4 variants lacking the MCM10 interaction domain were able to associate with replication factors such as the MCM7 and CDC45, but one of them showed a much reduced affinity for binding TOPBP1. Surprisingly, both mutants were able to largely support the viability of RECQ4-deficient DT40 cells, indicating that the interaction of RECQ4 with MCM10 is not essential for cell viability. Nevertheless, we found that this interaction is required for robust origin firing in vertebrate cells.

\section{RESULTS}

\section{RECQ4 and MCM10 interact directly in vitro and in human cells}

Previously, $\mathrm{Xu}$ and colleagues reported that a physical interaction exists between MCM10 and RECQ4 that requires the first 100 amino acids of RECQ4 [32]. In order to explore the cellular roles of the RECQ4-MCM10 interaction, we set out to map the MCM10 binding interface on RECQ4 molecule in finer detail. First, we confirmed that a YFP-RECQ4 fusion protein could interact with MCM10 in living cells. For this, we transiently expressed YFP-RECQ4 (or YFP alone as a control) in U2OS cells, and then immunoprecipitated the YFP proteins using GFP-Trap beads. We efficiently precipitated MCM10 together with RECQ4 from cells expressing YFP-RECQ4, but not those expressing YFP alone (Figure 1A). We then addressed at which stage of the cell cycle these two proteins interact. For this, we precipitated YFP-RECQ4 from asynchronous (AS), hydroxyurea (HU) arrested, and nocodazole (NOC) arrested cells. We observed that the RECQ4-MCM10 complex formed at all stages of the cell cycle and its abundance broadly mirrored that of the level of MCM10 protein (Figure 1B, 1C). Next, we analyzed whether RECQ4 and MCM10 are able to interact directly using purified recombinant proteins. We observed that GST-MCM10 could precipitate HIS-RECQ4, although GST alone could not, suggesting a direct physical interaction between RECQ4 and MCM10 (Figure 1D). To confirm this finding and to obtain an estimate of the $K_{\mathrm{d}}$ of the RECQ4-MCM10 interaction, we utilized Surface Plasmon Resonance. For this, the interaction of RECQ4 with GST-MCM10 immobilized on a CM3 chip was analyzed. This analysis confirmed that RECQ4 and MCM10 directly interact with a $K_{\mathrm{d}}$ value of approximately $170 \mathrm{nM}$ (Figure 1E). 


\section{Identification of the MCM10 interaction interface on RECQ4}

To accurately map the MCM10 binding interface on RECQ4, we utilized peptide arrays. The first 100 amino

A

PULL-

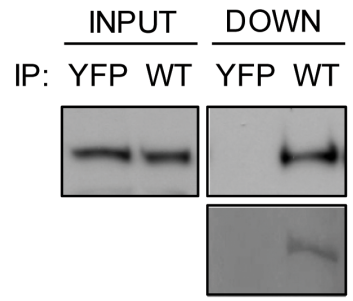

$\alpha-M C M 10$

YFP-RECQ4

(Ponceau S) acids of RECQ4 have been shown to be necessary for the interaction between the two proteins; however, it was not clear whether these residues were also sufficient for the interaction. Hence, we tested membrane-bound peptide arrays spanning amino acids 1-340 of RECQ4 (10 amino acids per peptide; a 5 amino acid overlap between each

B
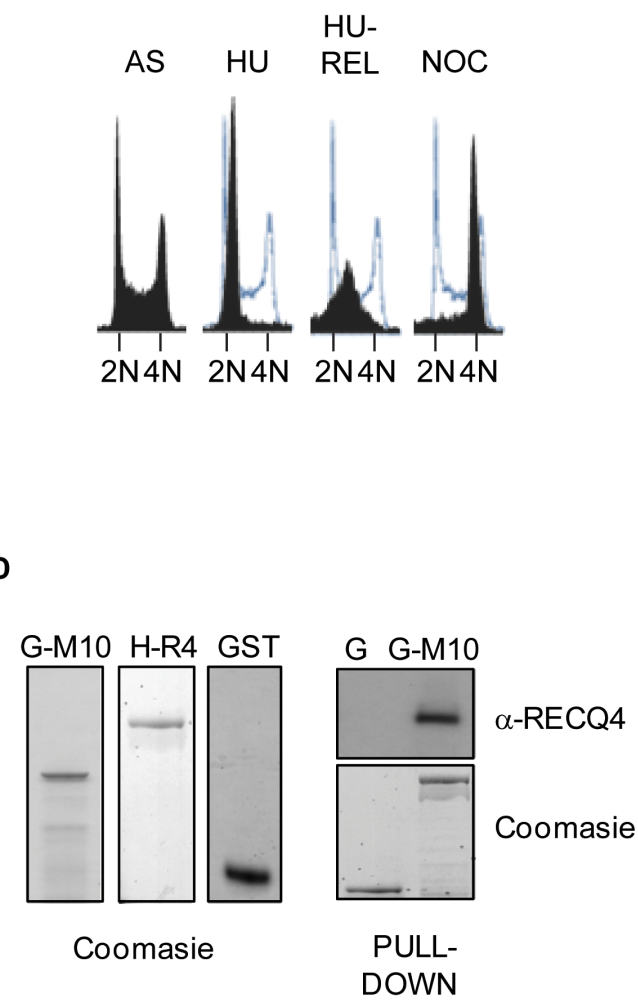

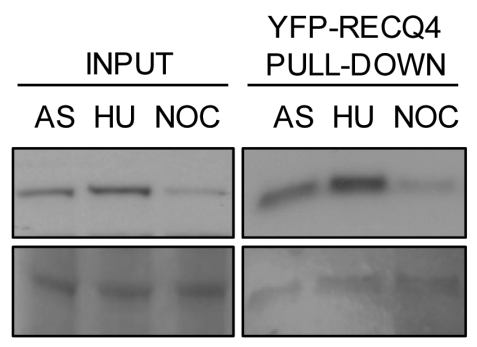

D

E
$\alpha-M C M 10$

YFP-RECQ4

(Ponceau S)

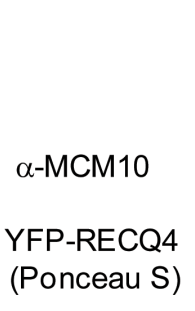

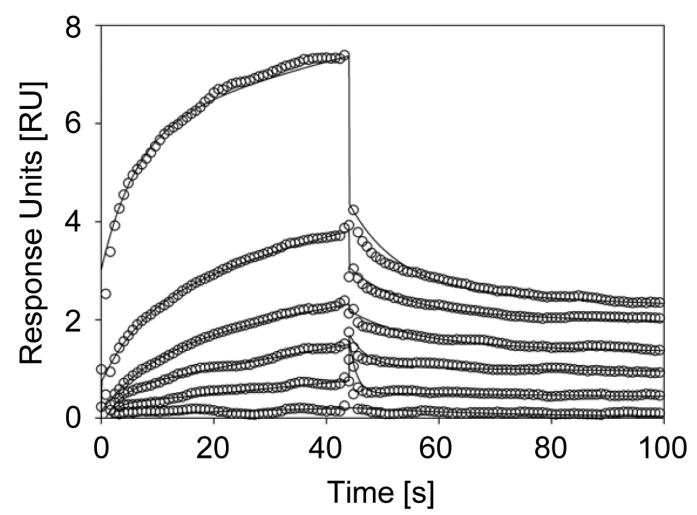

Figure 1: RECQ4 interacts directly with MCM10. A. Immunoblot analysis for MCM10 in anti-YFP immunoprecipitates from U20S cells expressing either YFP alone or YFP-RECQ4 (WT). Ponceau S staining was used to confirm the presence of YFP- RECQ4 in the precipitates. B. Flow cytometry analysis for asynchronous (AS), hydroxyurea-arrested (HU), HU-arrested cells released into S-phase (HUREL) and nocodozole arrested U20S cells (NOC). DNA was stained using propidium iodide. The solid black traces show the distribution of cells, and the blue traces show the outline of the control (AS) sample for comparison. C. Immunoblot analysis for MCM10 in anti-YFPRECQ4 immunoprecipitates from the cells shown in panel B. Loading is shown using Ponceau S staining. D. Coomassie blue stained polyacrylamide gels showing purified GST-MCM10 (G-M10), His-RECQ4 (H-R4) or GST alone (G and GST). The panel on the right shows immunoblot analysis for RECQ4 in GST pull-down samples, together with a Coomassie stained gel showing the loading control for the GST proteins. E. Binding kinetics analysis of RECQ4 interacting with immobilized MCM10 using surface plasmon resonance (Biacore). Open circles represent the experimental data at different RECQ4 concentrations $(1,0.5,0.25,0.125,0.06$, and $0.03 \mu \mathrm{M})$ and the solid lines represent the fit of the data to a two state model. The dissociation constant $\left(K_{\mathrm{d}}\right)$ was determined by the ratio of $k_{\text {on }}$ and $k_{\text {off }}$ and was found to be $170 \pm 200 \mathrm{nM}$. 
peptide). We then incubated the membrane with purified GST-MCM10 and analyzed any signal detected using an anti-MCM10 antibodies. The largest putative region of interaction spanned peptides 16-29, which corresponds to amino acids 76-145 of RECQ4 (Figure 2A, 2B, top panel, region designated $\mathrm{FL}$ ). This region appeared to comprise two sub-domains important for MCM10 binding between peptides 16-23 (designated ID1) and 25-29 (designated

A

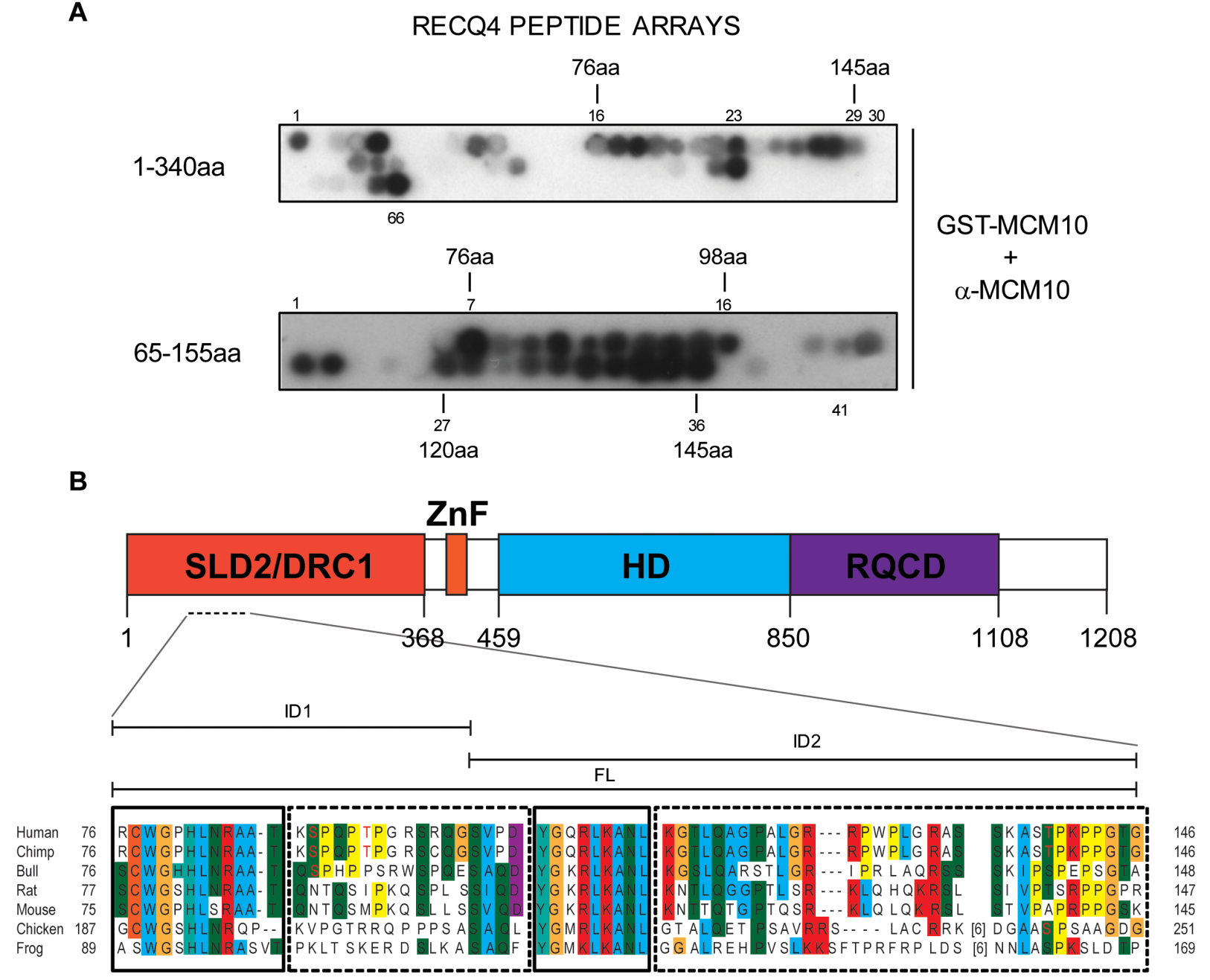

C

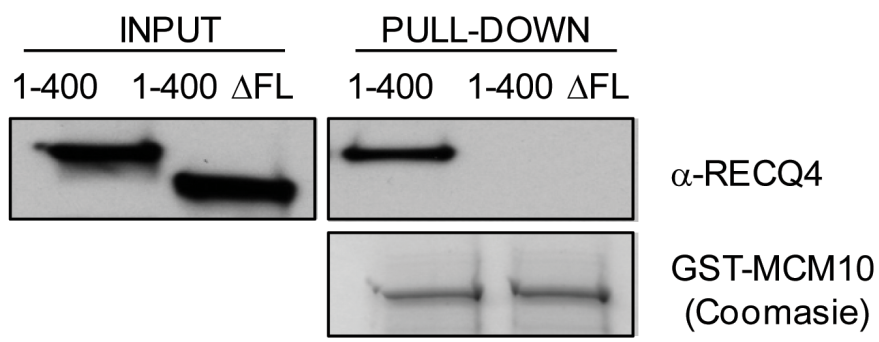

Figure 2: Mapping of the RECQ4-MCM10 interaction domain in RECQ4. A. Immunoblot analysis of two RECQ4 peptide arrays (residues 1-340; upper panel and 65-155; lower panel) after incubation of the membrane with purified GST-MCM10 and antiMCM10 antibodies. B. Sequence alignment of RECQ4 proteins from various species in the region of RECQ4 where MCM10 binds. Identical or very similar residue groups are colored. The solid boxes show highly conserved domains and the dashed boxes less highly conserved domains. The positions of the ID1, ID2 and FL regions are indicated above. The putative SP/TP target sites for Cdk's are shown in red text. C. Immunoblot analysis using anti-RECQ4 antibodies of protein pull-down using purified GST-MCM10. The input contained either MBP-RECQ4 1-400-HIS fragment or MBP-RECQ4 1-400-HIS with the $\Delta$ FL deletion, as indicated. 
ID2). These regions correspond to amino acid positions $76-120$ and 125-145, respectively. To further refine this analysis, we utilized a second peptide array spanning amino acids 66-155 (10 amino acids per peptide with a 9 amino acid overlap). This analysis provided further evidence for two distinct interfaces (amino acids 76-97 and 120-145) able to bind MCM10 (Figure 2A, 2B). Furthermore, bioinformatic analysis of the ID1 and ID2 interaction regions showed that they are well conserved in RECQ4 proteins across different species (Figure 2B).

\section{Disruption of the RECQ4-MCM10 interaction}

Next, we addressed whether deletion of the putative binding interface on RECQ4 could disrupt the interaction with MCM10. We generated a truncated variant of RECQ4 (RECQ4- $\triangle \mathrm{FL}$; with deletion of amino acids 75-145 in a fragment comprising residues 1-400 fused to MBP) (Figure 2B, 2C). Deletion of residues 75-145 in RECQ4 resulted in loss of the binding to MCM10, confirming that this region of RECQ4 contains residues necessary for the interaction (Figure 2C). We then asked if either or both of the aforementioned interfaces (ID1 and ID2) were important for the RECQ4-MCM10 interaction. For this, we generated two truncated YFP fusion protein variants of RECQ4; either RECQ4 lacking the FL domain (RECQ4- $\triangle F L$ ) or RECQ4 lacking just the ID1 interface (RECQ4- $\triangle \mathrm{ID} 1)$. Following transient expression in U2OS cells, the YFP fusion proteins were immunoprecipitated and associated proteins identified by immunoblotting. We observed that deletion of either the FL or the ID1 domain greatly diminished binding of RECQ4 to MCM10, as compared to wild-type RECQ4 (Figure 3A). This analysis indicated that ID1 was necessary for the interaction of

A

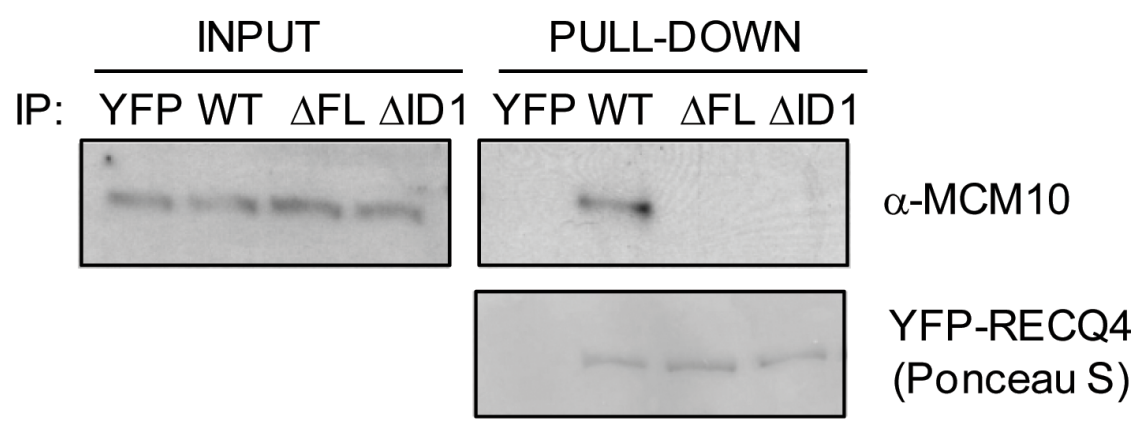

B

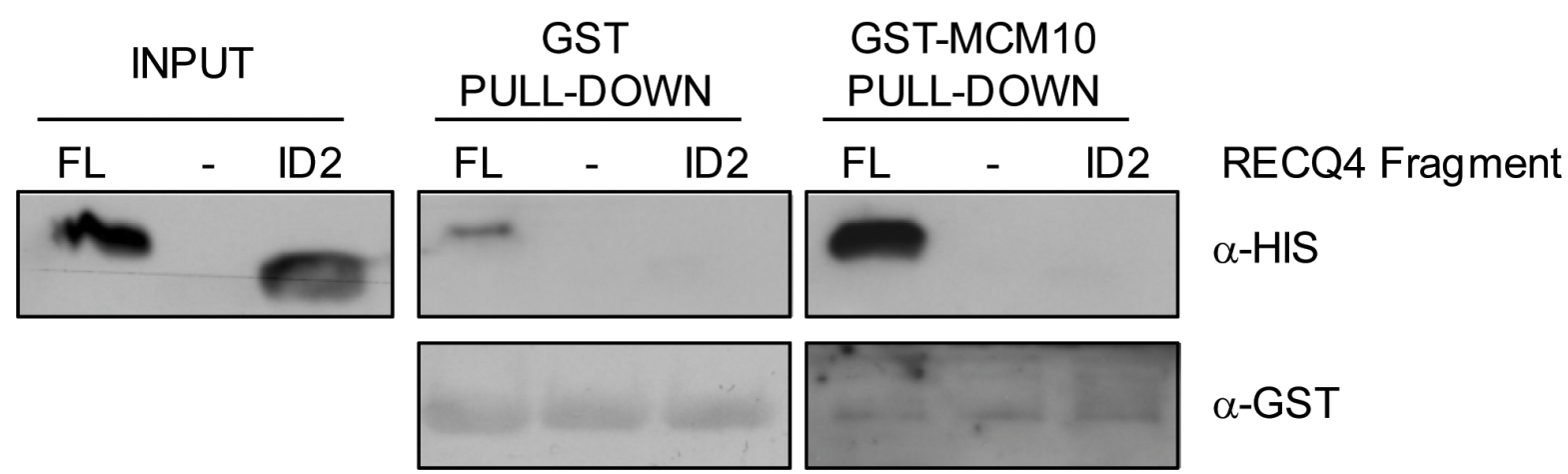

Figure 3: Characterisation of the RECQ4-MCM10 interaction in human cells. A. Immunoblot analysis using anti-MCM10 antibodies of protein immunoprecipitated using GFP-trap beads from U20S cells expressing YFP alone, YFP-RECQ4, YFP-RECQ4- $\Delta F L$ or YFP-RECQ4- $\triangle I D 1$. The precipitated YFP proteins were stained with Ponceau S, as indicated. B. Immunoblot analysis of His-tagged RECQ4 fragments (FL or ID2) pulled-down in vitro using either GST alone or GST-MCM10. Anti-GST immunoblot was used as a loading control. 
RECQ4 with MCM10 and that ID2 alone cannot suffice. Indeed, by analysis of recombinant FL and ID2 fragments prepared from E.coli, we observed that the FL domain, but not the ID2 domain, could interact with MCM10. These data indicate that the ID2 motif plays a minor role, if any, in directing the binding of RECQ4 to MCM10 (Figure 3B).

Interestingly, within the region of RECQ4 important for MCM10 binding there are three putative cyclindependent kinase (CDK) recognition sites at S89, T93 and T139. Previously, these sites have been shown to weakly affect the formation of the RECQ4-MCM10 complex in vitro when studies were conducted under specific (high salt) conditions [32]. Although these sites are not conserved between human RECQ4 and homologues in other species, we tested whether S89, T93 and T139 might be important for the formation of the RECQ4MCM10 complex in human cells. For this, we expressed versions of RECQ4 containing single or multiple alanine (non-phosphorylatable) or glutamic acid (to mimic phosphorylation) substitutions at these sites in U2OS cells. However, we observed no effect on the interaction with MCM10 (data not shown), suggesting that if modification of RECQ4 at these particular sites occurs in living cells, it plays a very minor role in the regulation of the RECQ4MCM10 interaction.

\section{Role of the RECQ4-MCM10 interaction in cells}

RECQ4 is an essential gene in mice, frogs, fruit flies and chicken cells, and is proposed to play a key role in the initiation of DNA replication $[15,31,33$, $35,50,51]$. We hypothesised that the RECQ4-MCM10 interaction might be essential for the establishment of functional replicons through facilitating robust origin activation, a role proposed for the yeast homologues of these proteins; Sld2/Drc1 and Mcm10/Cdc23 (reviewed in [52]). To study whether the interaction between human RECQ4 and MCM10 is essential for cell viability, we took advantage of a conditional RECQ4 gene deletion in the chicken DT40 cell line [31]. RECQ4-// $:$ hFLAG-RECQ4 cells do not express endogenous chicken RECQ4, but maintain viability due to the presence of a human FLAGRECQ4 transgene under the control of a doxycyclineregulated promoter (Tet-OFF system). It has been shown previously that within 48 hours of repression of human FLAG-RECQ4 protein expression, the RECQ4-deficient chicken cells cease to proliferate [31]. We generated stable DT40 cell clones expressing either YFP-RECQ4$\triangle F L$ or YFP-RECQ4- $\triangle$ ID1 (or YFP-RECQ4 wild-type as a control) from the CMV promoter in the $R E C Q 4^{-1 /-}$ $\because h F L A G-R E C Q 4$ background. As expected, we could efficiently downregulate expression of the FLAG-RECQ4 transgene, but not the transfected human YFP-RECQ4, using doxycycline (Figure $4 \mathrm{~A}$ and data not shown). To address whether these variants could support chicken cell viability in the absence of any wild-type RECQ4, the expression of FLAG-hRECQ4 was repressed by addition of doxycycline, and cell number was monitored over the next 72 hours. As expected, the DT40 cells lacking the YFP-RECQ4 transgene ceased to proliferate, unlike the cells expressing YFP-RECQ4 (Figure 4B). Interestingly, we could detect a partial, but significant, proliferation deficit in cells expressing RECQ4- $\Delta$ FL or RECQ4- $\Delta$ ID1 (Figure 4B). We conclude that the MCM10 interaction domain in RECQ4 is not essential for cell viability, but is required to support a robust level of cell proliferation. One possible explanation for this is that the YFP-RECQ4$\Delta \mathrm{FL}$ and $-\Delta \mathrm{ID} 1$ proteins might display an altered pattern of nuclear localisation; however, we observed that this was indistinguishable from that of wild-type YFP-RECQ4 (Figure 4C and data not shown).

To examine the possibility that the RECQ4$\triangle \mathrm{MCM} 10$ expressing cells might have altered cell cycle distribution, we repressed the FLAG-hRECQ4 transgene in cells expressing the YFP-RECQ4- $\triangle F L$ variant, and then arrested the cells in prometaphase using nocodazole. We then monitored cell cycle progression using flow cytometry following release of cells from this arrest into the next cell cycle (Figure 5A). Cells expressing the $\Delta \mathrm{FL}$ mutant were proficient for an arrest in prometaphase induced by nocodazole, but following release showed a small but consistent alteration in the rate of progression through the G1 and S phases (Figure $5 \mathrm{~A}$ and data not shown). This was consistent with the observed proliferation defect. From this we conclude that the interaction between RECQ4 and MCM10 influences normal cell cycle progression.

\section{The RECQ4-MCM10 interaction is required for robust replication origin firing}

To explain the observed phenotypes we explored several possibilities. We hypothesised that loss of the interaction with MCM10 might affect the chromatin localisation of RECQ4, its ability to form stable complexes with other replication factors, or the efficiency of replication origin firing. Previous studies in human cells revealed that RNAi-mediated depletion of MCM10 in HeLa cells disrupts the localisation of RECQ4 to chromatin [53]. Therefore, we addressed whether a RECQ4 variant unable to bind MCM10 could be still recruited to the chromatin in living cells. We transiently expressed wild-type and RECQ4 variant lacking the MCM10 interaction domain in U2OS cells that had been exposed to siRNAs that downregulate the endogenous RECQ4. We then performed a sub-cellular fractionation procedure. We could detect robust chromatin association for the RECQ4- $\triangle$ ID1 (Figure 5B). This indicated that RECQ4 binding to the chromatin was largely independent of the MCM10 interaction domain and suggested, in 
A

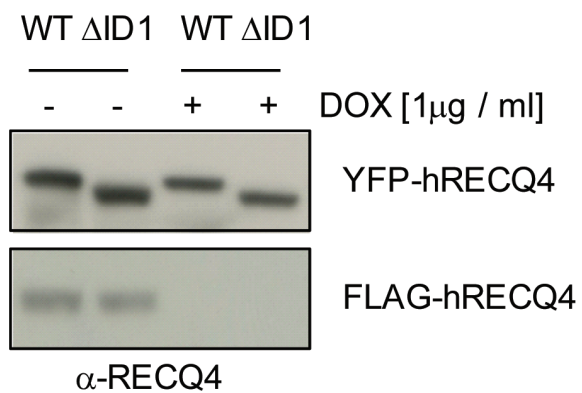

B

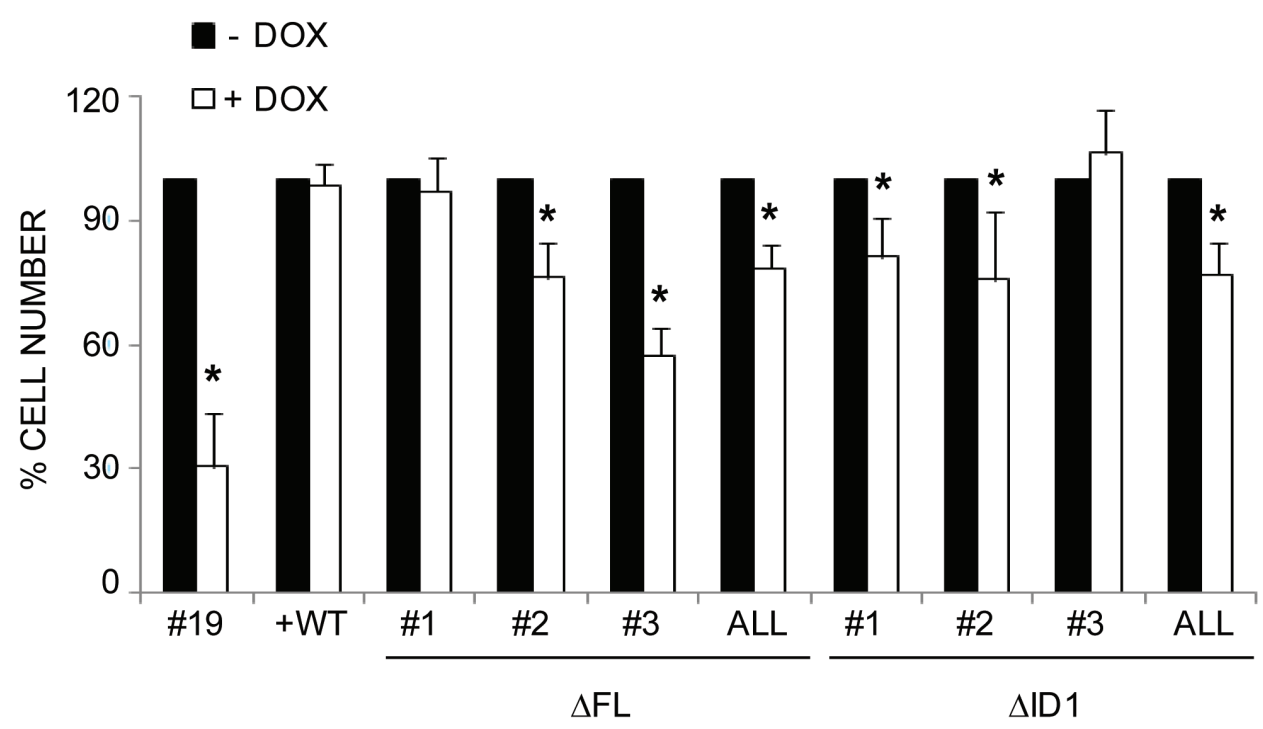

C

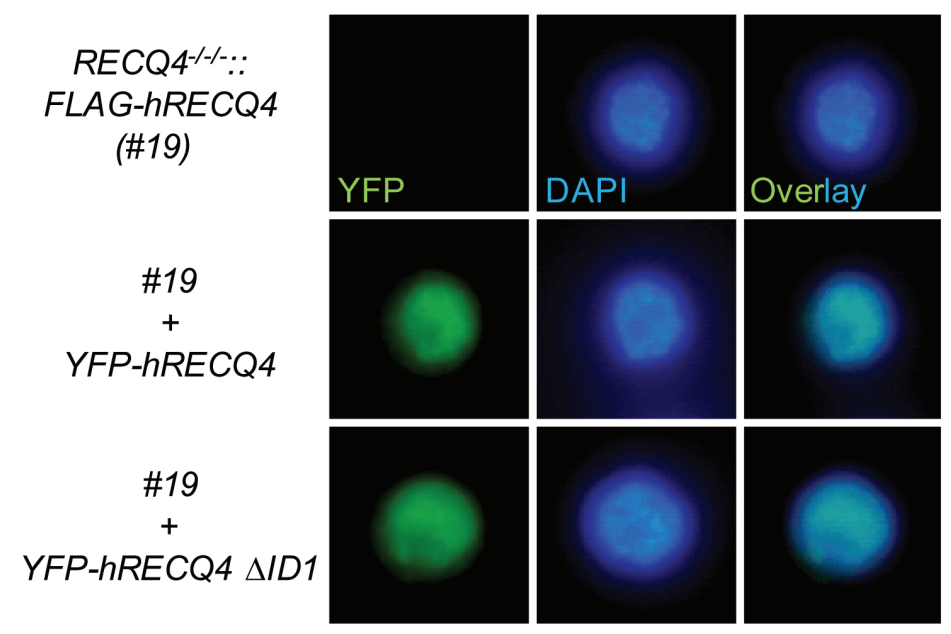

Figure 4: Analysis of RECQ4 variants in chicken DT40 cells (clone \#19) containing a conditional RECQ4 mutation. A. Western blotting analysis using anti-RECQ4 antibodies of DT40 extracts from cells grown with (+) or without (-) doxycycline. Note that expression of the transgene (FLAG-RECQ4) is repressed by doxycycline but the transfected YFP-RECQ4 is not. B. Quantification of cell number 72 hours after addition of doxycycline (+) or mock treated (-). Three independent clones for each of the mutant RECQ4 variants $(\triangle \mathrm{FL}$ or $\triangle \mathrm{ID} 1)$ are shown, together with the average of the three (ALL). Error bars represent SD from at least three independent experiments. C. Direct fluorescence analysis of cells expressing no human RECQ4 (top panel), YFP-RECQ4 (middle) or YFP-RECQ4$\triangle I D 1$ (bottom). Note the localization of the YFP proteins to the nucleus, as shown by DAPI staining of DNA. 
contrast to a previous report, that RECQ4 does not require MCM10 for its chromatin localisation [53].

MCM10 is known to be important for the association of RECQ4 with the MCM2-7 helicase [32], for the assembly of CMG complexes (CDC45-MCM27-GINS), and for robust origin firing in human cells $[35,53]$. Therefore, we analyzed whether the loss of the MCM10 binding domain affected the ability of RECQ4 to form specific protein complexes. We expressed YFP alone, YFP-RECQ4 wild-type, YFP-RECQ4- $\triangle F L$ and
YFP-RECQ4- $\triangle$ ID1 in U2OS cells, immunoprecipitated the YFP-containing proteins, and then immunoblotted for known replication factors. We observed that, as expected, the two mutant RECQ4 variants did not coimmunoprecipitate MCM10 (Figure 6A). Nevertheless, these RECQ4 variants were able to co-immunoprecipitate several other DNA replication factors, including MCM7, TRESLIN and CDC45 (Figure 6A). These data are inconsistent with a previous report indicating that MCM10 is required for the association of RECQ4 with the MCM2-

\section{A \\ NOCODAZOLE ARREST AND RELEASE}

G1 phase

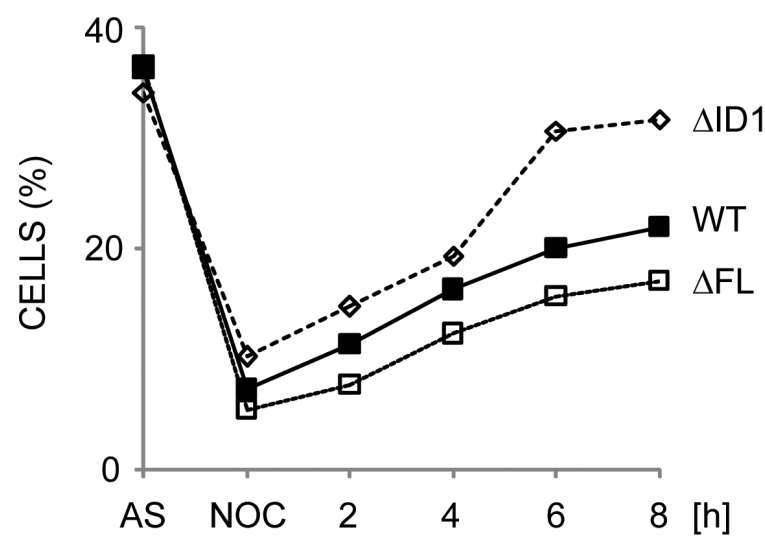

S phase

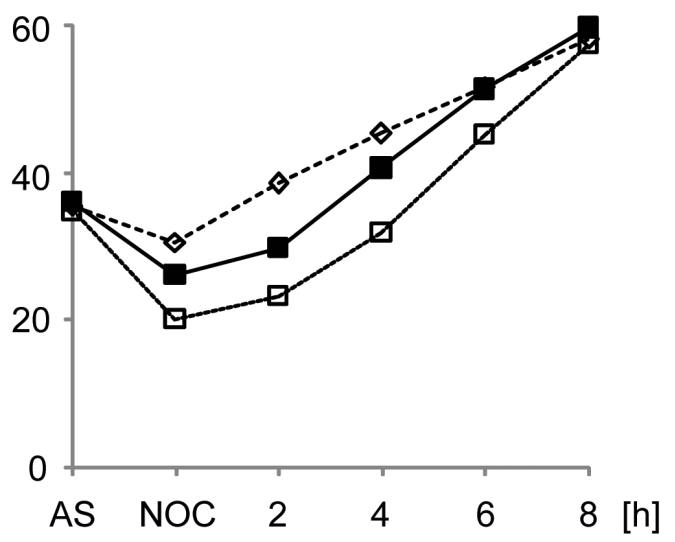

B

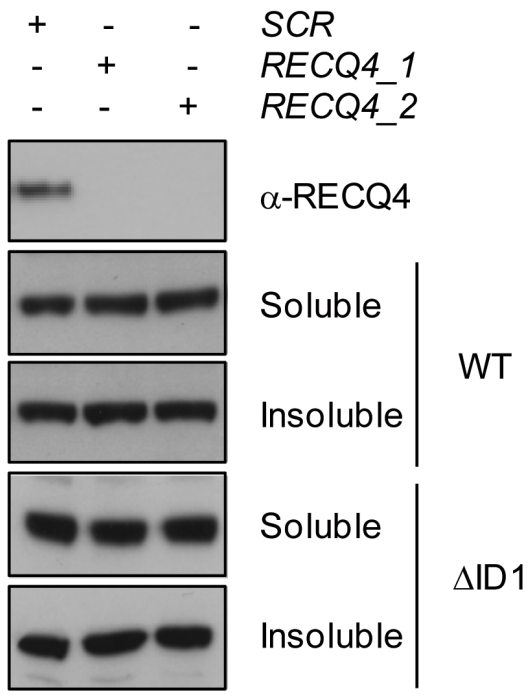

Figure 5: RECQ4-MCM10 interaction is required for normal cell cycle progression but not for RECQ4 chromatin localization. A. Analysis of cell cycle transit time using flow cytometry. DT40 cells expressing YFP-RECQ, YFP-RECQ4- $\Delta$ FL or - $\Delta$ ID1, as indicated, were arrested with nocadazole (NOC) and released into the next cell cycle for up to 8 hours. Points are the mean of three independent experiments. B. Western blotting analysis of cell extracts from U20S cells transfected with either of two independent siRNAs targeting RECQ4 (1 and 2) or a scrambled siRNA control (SCR). Note that the endogenous RECQ4 is depleted (top panel) but the transfected, siRNA-resistant WT RECQ4 WT and RECQ4- $\triangle \mathrm{ID} 1$, are not. 
A

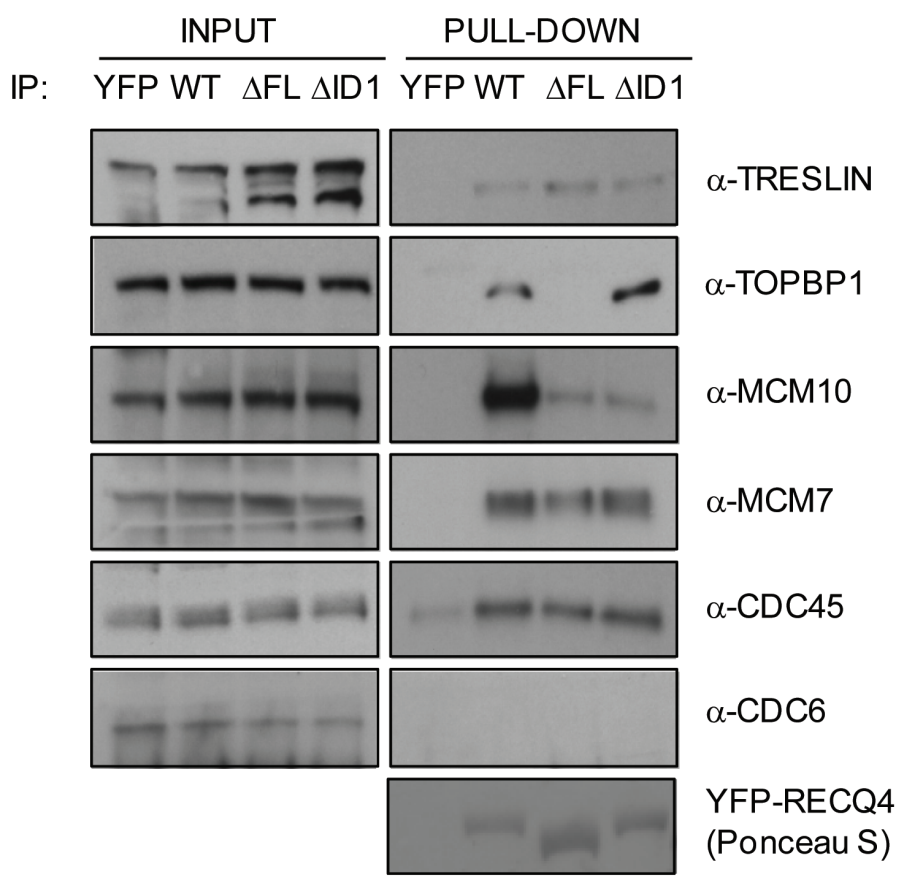

B
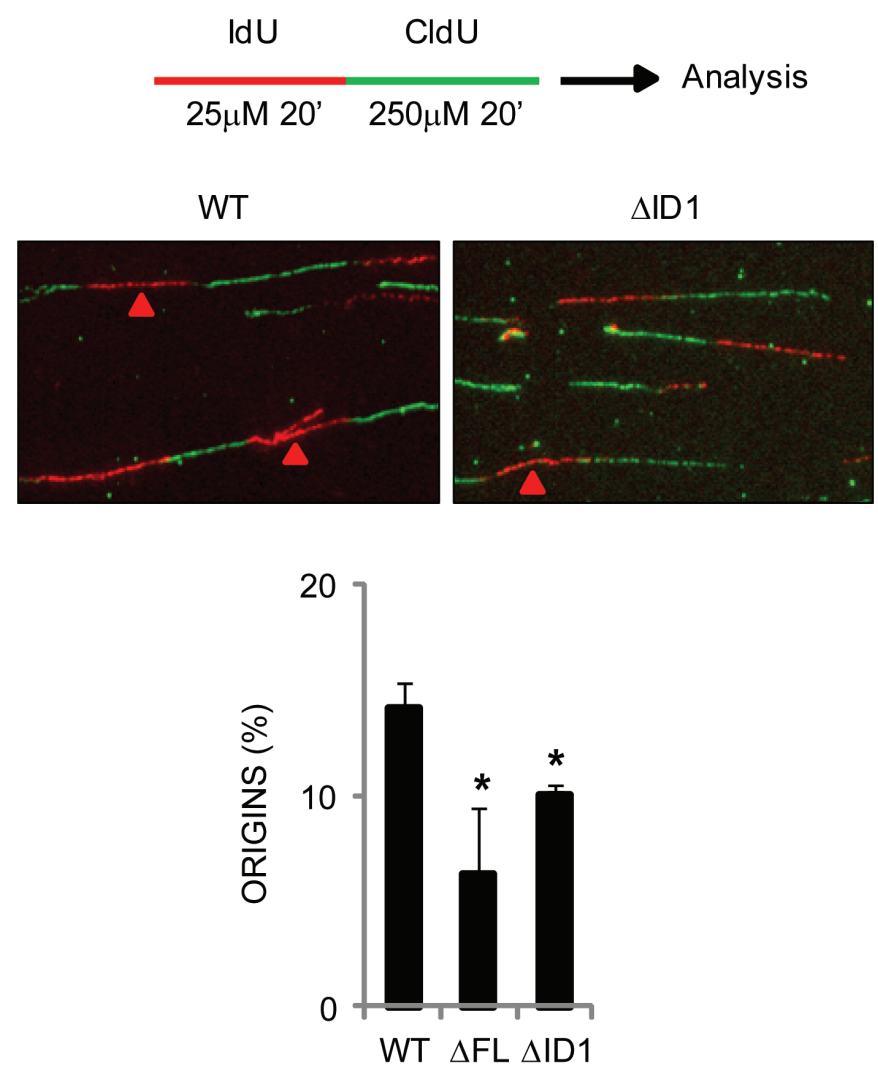

Figure 6: Analysis of protein complexes associated with the truncated RECQ4 variants and their ability to support normal DNA replication in DT40 cells. A. Western blotting analysis of proteins pulled-down using YFP alone, YFP-RECQ4, or the $\Delta \mathrm{FL}$ and $\Delta \mathrm{ID} 1$ variants. The input samples for each pull down are shown. The proteins analyzed are shown on the right. Ponceau $\mathrm{S}$ staining was used to confirm a similar loading of the YFP-RECQ4 proteins. B. DNA replication analysis on isolated DNA fibres. The upper cartoon shows the sequential labeling protocol using IdU (red) and CldU (green) nucleoside analogues. The middle panel shows representative fibres. Red arrows devote red tracts flanked by green tracts, denoting the positions of replication origins. The lower panel shows relative frequency of origin firing events. Error bars represent SD from three independent experiments. ${ }^{*}=p<0.05$. 
7 helicase, but consistent with the fact that budding yeast Sld2 can interact directly with the replicative helicase $[32,54]$. Interestingly, the $\Delta \mathrm{ID} 1$ protein, but not the $\Delta \mathrm{FL}$ variant, could efficiently co-precipitate TOPBP1 (Figure $6 \mathrm{~A})$. We conclude that the $\triangle \mathrm{FL}$ variant shows altered interaction with MCM10 and TOPBP1, but retains that ability to bind several other DNA replication factors.

Next, we analyzed whether the RECQ4-MCM10 interaction might influence the efficiency of replication origin firing. For this we utilized a dual labelling protocol to define the position of active replicons in isolated DNA fibres. We pulse labelled the DNA of cells expressing the wild-type or mutant RECQ4 proteins with IdU and CldU, extracted DNA fibres and quantified the frequency of different replication structures (Figure 6B). We could readily observe labelling patterns indicative of replication origins, ongoing forks and termination events. We observed a significantly reduced number of origin-containing labelled tracts in cells expressing the mutant variants compared to wild-type RECQ4 (Figure $6 \mathrm{~B})$. These data are consistent with the proposed role of RECQ4 in the initiation of DNA replication and indicate that the interaction between MCM10 and RECQ4 is important for supporting the efficient firing of replication origins.

\section{DISCUSSION}

Our analysis of RECQ4-MCM10 interaction has identified two regions within the Sld2-like N-terminus of RECQ4 that are essential for MCM10 binding. We showed that the interaction between RECQ4 and MCM10 is partially required for viability of chicken cells lacking endogenous RECQ4, and for normal replication origin firing. However, this interaction is not required for localisation of RECQ4 with chromatin or its association with replication factors such as MCM7, TRESLIN or CDC45. These data indicate that the formation of RECQ4-MCM10 complex plays important roles in the progression of the cell cycle and normal cell proliferation through activation of active origins of replication during $\mathrm{S}$ phase. Moreover, the FL domain was shown to contain a sequence important for efficient formation of a RECQ4TOPBP1 complex.

Recent work suggested that yeast Sld2 binds to origins of replication before $\mathrm{Mcm} 10$, and that this prior binding is a prerequisite for the association of MCM10 with chromatin [47]. Budding yeast Mcm10 has been proposed to be involved in a novel step in replication initiation after the assembly of CMG complexes onto origins, suggesting a role in the latter stages of the initiation of DNA replication $[46,55]$. In contrast, in HeLa cells, depletion of MCM10 causes loss of RECQ4 chromatin localisation [53], suggesting a different mechanism may be operating in human cells. However, we observed that human RECQ4 could be recruited to the chromatin independently of MCM10, indicating that loading of RECQ4 onto chromatin may occur prior to recruitment of MCM10. The discrepancies between our study and results of $\mathrm{Xu}$ and colleagues [32] could be explained by different approaches used. We analyzed an interaction-defective mutant that allowed us to explore directly the relationship between MCM10 and RECQ4, whereas $\mathrm{Xu}$ and colleagues used MCM10 depletion. It is plausible that in MCM10-depleted cells, the structure of replication origins or the composition of the origin-bound protein complex might be fundamentally different from those in the control cells, thus preventing the recruitment of RECQ4.

Recent work by the Pospiech and Krejci laboratories, has described multiple DNA binding interfaces in RECQ4 [37-39]. Interestingly, these DNA binding regions lie within the Sld2-like domain of RECQ4 and show strong preferential binding towards G4 quadruplexes. Such sequences are potetially also found in the proximity of origins of DNA replication [3, 37]. Although our unpublished data indicate that the FL interaction domain severely affects the DNA binding affinity of RECQ4 in vitro, it is unlikely that this mutant behaves similarly in the cellular context. It would be surprising if significant loss of the DNA binding activity would only partially affect the cellular roles of this essential helicase, as we observed in our experiments. An obvious explanation for this finding is that there is likely to be at least one additional binding domain in the RECQ4 molecule.

Patients bearing RECQ4 mutations mainly express RECQ4 C-terminal truncations sparing the N-terminal Sld2-like domain that is essential for cell viability (reviewed in [18]). This strongly suggests that the essential functions of RECQ4 are associated with initiation of DNA replication and are not dependent on its helicase activity $[15,31,32,35]$. Indeed, RECQ4-deficient adult mice show hematopoietic abnormalities, including bone marrow failure caused by $\mathrm{S}$ phase arrest and apoptosis, which can be rescued by expression of a helicase-dead mutant of RECQ4 [56]. We hypothesised that the loss of the RECQ4MCM10 interaction site that is located within the essential domain of RECQ4 might result in cell lethality. We found that the RECQ4-MCM10 interaction was required for normal cell cycle progression and for robust origin firing; however, it was not essential for viability, suggesting that if the essential functions of RECQ4 helicase are associated with initiation of DNA replication, they are not mediated via an interaction with MCM10. Interestingly, previous observations using the chicken cell system indicated that the entire 1-496 amino acid N-terminal domain is required for cell viability. Hence, the RECQ4- $\triangle$ ID1 and RECQ4$\triangle \mathrm{FL}$ mutants we studied represent the only variants described thus far lacking a region of the N-terminal domain that are able to rescue the viability of vertebrate cells lacking endogenous RECQ4.

The mild phenotype of cells expressing RECQ4 
variants that cannot bind MCM10 is likely explained by the observation that these variants can still interact with other replication factors, including MCM7, TRESLIN and CDC45. The ability of the $\triangle F L$ mutant to rescue viability of DT40 cells, while lacking an interaction with TOPBP1, suggests that RECQ4 might act in a mechanistically distinct way than the Sld2/Drc1, as their interactions with Dpb11/Rad4 is essential for viability in yeast $[8,9]$. However, at this stage and without further dissection of the essential cellular functions of RECQ4, this remains conjecture. One final outcome of our study is based on the finding that the $\triangle \mathrm{FL}$, but not the ID1, mutant failed to efficiently form a complex with TOPBP1, but was still able to rescue viability of DT40 cells. This suggests that the ID2 domain likely contains a TOPBP1 interacting motif. Future studies on this putative domain would likely be valuable for our understanding the functions of RECQ4 in human cells.

\section{MATERIALS AND METHODS}

\section{Gene cloning}

The human GST-MCM10 construct was a kind gift from Dr. Yilun Liu (pGEX-4T-1-MCM10) [32]. Human RECQ4 cDNA was cloned into pEYFPC1 (Clontech) between SalI and XbaI sites. Fragments of human RECQ4 corresponding to amino acids 76-145 (RECQ4-MCM10 FL) and amino acids 105-145 (RECQ4-MCM10 ID2 domain) were cloned into $\mathrm{pET} 14 \mathrm{~b}$ (Novagen) via $\mathrm{pGEMT}$ Easy (Promega) with 5'-GGA TCC GCG CTG CTG GGG GCC C-3', 5'-GGA TGT ACC TGG GGG CTT TGG GG-3' and 5'-GGA TCC GGG GCA GCG GCT CAA3' and 5'-GGA TCC TGT ACC TGG GCG CTT TGG GG-3' oligunucleotides, respectively, using Takara LA Taq polymerase (Clontech). To create deletion of MCM10 interaction domain inhuman RECQ4- $\Delta \mathrm{FL}$ and RECQ4$\triangle \mathrm{ID} 1$ extra SacII restriction site was introduced by site directed mutagenesis in the pEYFPC1-RECQ4 vector with 5'-GGTACAGGGCCTGTCCCCTCCGCGGCAGAAA AAGTCAGTGATGAGCCTCC-3',5'-GGAGGCTCA TCACTGACTTTTTCTGCCGCGGAGGGGACAGG CCCTGTACC-3' and 5'-GGC GGA GCC GCC AGG $\underline{\mathrm{CCG}} \mathrm{CGG}$ TGC CGG ACT ACG-3, 5'-CGT AGT CCG GCA CCG $\underline{\mathrm{CGG}} \mathrm{CCT}$ GGC GGC TCC GCC3 'oligonucleotides, respectively (mutated bases are underlined). Mutated plasmids were then recovered from E.coli TOP10 (Life Technologies), digested with SacII and re-ligated to create appropriate deletion. To generate alanine and glutamic acid substitutions of S89, T93 and $\mathrm{T} 139$ the point mutations were introduced by site directed mutagenesis in the pEYFPC1-RECQ4 vector with the following oligonucleotides: S89A 5'-CGG GCT GCG ACC AAG GCA CCA CAG CCT ACG CCA G-3' and 5'-

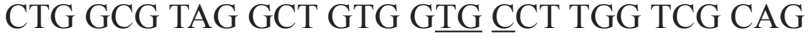
CCC G; S89E 5'-GAA TCG GGC TGC GAC CAA GGA GCC ACA GCC TAC GCC AGG G-3' and 5'-CCC TGG CGT AGG CTG TGG CTC CTT GGT CGC AGC CCG ATT C-3'; T93A 5'-GAC CAA GAG TCC ACA GCC

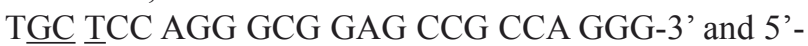
CCC TGG CGG CTC CGC CCT GGA GCA GGC TGT GGA CTC TTG GTC-3'; T139A 5'-GCC TCA TCT AAG

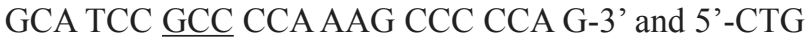
GGG GCT TTG GGG CGG ATG CCT TAG ATG AGG C-3'; T139E 5'-GCC TCA TCT AAG GCA TCC $\underline{\text { GAG }}$ CCA AAG CCC CCA GGT AC-3' and 5'-GTA CCT GGG

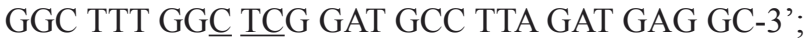
S89A/T93E 5'-GAC CAA GGC ACC ACA GCC TGC TCC AGG GCG GAG CCG CCA GGG-3' and 5'-CCC TGG CGG CTC CGC CCT GGA GCA GGC TGT GGT GCC TTG GTC-3' using the pEYFPC1-RECQ4 S89A as a template; S89E/T93E 5'-GCG ACC AAG GAG CCA CAG CCT GAG CCA GGG CGG AGC CG-3' and 5'CGG CTC CGC CCT GGC TCA GGC TGT GGㅡㅡ TCC TTG GTC GC-3' using pEYFPC1-RECQ4 S89E as a template (mutated bases are underlined). Site directed mutagenesis reactions were performed using Phusion High-Fidelity Polymerase (Thermo Scientific). The MBPRECQ4-HIS 1-400 and 1-400 $\Delta \mathrm{FL}$ was generated by sub-cloning of RECQ4 cDNA fragment from pEYFPC1RECQ4 WT or $\triangle \mathrm{FL}$ constructs into pMAL-c2x-9HIS.

\section{Antibodies}

Primary antibodies used were as follows: rat antiBrdU (clone BU1/75 ICR1 for CldU detection, Abcam) at 1:40, mouse anti-BrdU (clone B44 for IdU detection, Beckton Dickinson) at 1:2, mouse anti-human CDC6 (sc9964, Santa Cruz) at 1:1000, rabbit anti-human CDC45 (15678-1-AP, Protein Tech Group) at 1:500, mouse antiHIS (clone HIS-1, Sigma) at 1:1000, mouse anti-human MCM7 [57] at 1:500, rabbit anti-human MCM10 (122511-AP, Protein Tech Group) at 1:1000, rabbit anti-human RECQ4 [58] at 1:1000, rabbit anti-human TOPBP1 (A300-111A, Bethyl Laboratories) at 1:1000, rabbit antihuman TRESLIN (A303-472A, Bethyl Laboratories) at $1: 1000$.

\section{Cell culture and microscopy}

Human osteosarcoma cells (U2OS) were cultured in Dulbeco's Modified Eagle Medium (DMEM) Glutamax (Life Technologies) with 10\% fetal bovine serum (Life Technologies) and $1 \%$ penicillin/streptomycin (Life Technologies) at $37^{\circ} \mathrm{C}$ in humidified $5 \% \mathrm{CO}_{2}$ atmosphere. Chicken DT40 B-lymphoma cells were cultured in Roswell Park Memorial Institute-1640 Medium (RPMI1640) Glutamax (Life Technologies) with 10\% fetal bovine serum (Life Technologies), 1\% chicken serum 
(Life Technologies) and 1\% penicillin/streptomycin (Life Technologies) at $39.5^{\circ} \mathrm{C}$ in humidified $5 \% \mathrm{CO}_{2}$ atmosphere with doxycycline $(1 \mu \mathrm{g} / \mathrm{ml}$, Sigma) where indicated. For nocodazole arrest, cells were pre-treated with doxycycyline for $80 \mathrm{~h}$ and then nocadazole was added to the final concentration of $500 \mathrm{ng} / \mathrm{ml}$ for $16 \mathrm{~h}$. Microscopy was performed with a Nikon Eclipse 80i, using x100 (NA 1.40) or x60 (NA 1.40) objectives and Nikon ACT-1 version 2.62 software (Nikon).

\section{Cell transfection}

For transient transfections of U2OS cells, 70-80\% confluent cultures in $10 \mathrm{~cm}$ dishes were transfected using $30 \mu \mathrm{l}$ of Lipofectamine 2000 reagent (Life Technologies), $1 \mathrm{ml}$ OPTI-MEM medium (Life Technologies) and $6 \mu \mathrm{g}$ of DNA. Cells were analyzed or harvested $48 \mathrm{~h}$ post-transfection. For siRNA treatments, $10^{5}$ U2OS cells were transfected by mixing with siRNA solution (10 nM siRNA (Sigma), $5 \mu$ l Lipofectamine 2000 (Life Technologies) and $400 \mu \mathrm{l}$ OPTI-MEM media (Life Technologies)). After $72 \mathrm{~h}$, cells were transfected with the RECQ4 cDNA. The RECQ4 siRNAs targeted the 3'UTR; RECQ4-1:5'-GGAACGAGGAGGCUCCA AAdTdT-3' 5'-UUUGGAGCCUCCUCGUUCCdTdT-3'; RECQ42: 5'-GUUGUCAGAGGCUAGGGCAdTdT-3' and 5'-UGCCCUAGCCUCUGACAACdTdT-3'. To obtain stably expressing chicken clones, $10^{7}$ DT40 cells were harvested and washed once with phosphate buffered saline (PBS), re-suspended in $500 \mu$ l of PBS. Approximately 25 $\mu \mathrm{g}$ of linearized plasmid DNA was added to the cells, and the mixture was incubated for $10 \mathrm{~min}$ on ice. Cells were then transfected in $0.4 \mathrm{~cm}$ cuvettes (Bio-Rad) in Gene Pulser XCell with CE Module (Bio-Rad) at $300 \mathrm{~V}$ and $600 \mu \mathrm{F}$ settings, and were then incubated on ice for an additional $10 \mathrm{~min}$. Transfected cells were then transferred to $20 \mathrm{ml}$ pre-warmed medium. $16-18 \mathrm{~h}$ post-transfection, cells were exposed to geneticin (Life Technologies) at 2 $\mathrm{mg} / \mathrm{ml}$ and transferred to 96 well plates to obtain single colonies.

\section{Protein purification}

A full length RECQ4 construct was a kind gift from Dr Yilun Liu. RECQ4 was purified essentially by the procedure described by [34]. The protein was expressed in Rosetta pLysS cells following growth at $18^{\circ} \mathrm{C}$ in medium containing $0.1 \mathrm{mM}$ IPTG for $16 \mathrm{~h}$. The cells were harvested and lysed in buffer A (50 mM potassium phosphate, $\mathrm{pH}$ 8, $300 \mathrm{mM} \mathrm{KCl}, 10 \%$ glycerol, $0.5 \mathrm{mM}$ TCEP, $0.5 \%$ Triton X-100, 1 tablet/50 ml Complete Inhibitor cocktail EDTA Free (Roche), $50 \mathrm{U} / \mathrm{ml}$ Benzonase, $1 \mathrm{mM}$ PMSF, $0.1 \mathrm{mg} / \mathrm{ml}$ lysozyme). The cell suspension was lysed using a French press and clarified by centrifugation.
The cleared lysate was loaded onto HQ sepharose beads (GE Healthcare) and the flow through was collected and $0.1 \%(\mathrm{~W} / \mathrm{V})$ polyethyleneimine (PEI) was added and stirred for $30 \mathrm{~min}$ at $4^{\circ} \mathrm{C}$. The precipitate was clarified by centrifugation and the supernatant was loaded on to a HiTrap HP column (GE Healthcare). The column was washed with buffer $\mathrm{B}(50 \mathrm{mM}$ potassium phosphate, $\mathrm{pH}$ $6.0,500 \mathrm{mM} \mathrm{KCl}, 10 \%$ glycerol, $0.5 \%$ Triton X-100, $0.5 \mathrm{mM}$ TCEP, $10 \mathrm{mM}$ imidazole), and the bound protein was eluted with Buffer B containing $1 \mathrm{M}$ imidazole. The eluted RECQ4 protein was buffer exchanged with $50 \mathrm{mM}$ Tris $\mathrm{pH} 7.5,500 \mathrm{mM} \mathrm{KCl}, 10 \%$ glycerol and $0.5 \mathrm{mM}$ TCEP (Buffer C) and was then incubated with 100-120 $\mu 1$ FLAG M2 beads (Sigma) overnight at $4^{\circ} \mathrm{C}$. The bound protein was washed with Buffer $\mathrm{C}$ and eluted with Buffer C containing 200-300 $\mu \mathrm{g} / \mathrm{ml}$ FLAG peptide and buffer exchanged with Buffer C.

Fragments of MBP-RECQ4-HIS 1-400 and 1-400 $\Delta 65-145$ were purified from $E$. coli BL21(DE3) pLysS cells previously induced with $0.1 \mathrm{mM}$ IPTG at $\mathrm{OD}_{600}=0.6$ for $16-20 \mathrm{~h}$ at $16^{\circ} \mathrm{C}$. For MBP-RECQ4HIS fragments, the cell pellet was re-suspended in lysis buffer $(50 \mathrm{mM}$ Tris- $\mathrm{HCl}, \mathrm{pH} 7.5,10 \%$ sucrose, $2 \mathrm{mM}$ EDTA, $200 \mathrm{mM} \mathrm{KCl,} \mathrm{0.01 \%} \mathrm{NP-40,}$ $1 \mathrm{mM}$ 2-mercaptoethanol) supplemented with protease inhibitors (aprotinin, chymostatin, leupeptin, pepstatin A and benzamidine hydrochloride at $5 \mathrm{mg} / \mathrm{ml}$ each). Cells were then lysed by sonication, and the supernatant was clarified by centrifugation at $100,000 \mathrm{~g}$ for $1 \mathrm{~h}$ at $4^{\circ} \mathrm{C}$. MBP-RECQ4-HIS was precipitated using HIS-Select nickel affinity gel (Sigma) at $4^{\circ} \mathrm{C}$ overnight. Beads were washed with buffer $\mathrm{K}\left(20 \mathrm{mM} \mathrm{K} \mathrm{HPO}_{4}, 10 \%\right.$ glycerol, $0.5 \mathrm{mM}$ EDTA, $150 \mathrm{mM} \mathrm{KCl,} 0.01 \% \mathrm{NP}-40$, $1 \mathrm{mM} \beta$-mercaptoethanol) containing $10 \mathrm{mM}$ imidazole. The bound protein was eluted by buffer $\mathrm{K}$ containing increasing concentrations of imidazole (150-1000 mM). Fractions containing MBP-RECQ4-HIS were incubated with amylose beads (NEB) at $4^{\circ} \mathrm{C}$ for $1 \mathrm{~h}$. The beads were then washed with buffer $\mathrm{K}$ and proteins eluted with buffer $\mathrm{K}$ supplemented with $10 \mathrm{mM}$ maltose. Pooled fractions containing MBP-RECQ4-HIS protein were loaded onto MonoS column (GE Healthcare) and eluted using salt gradient (150-1000 $\mathrm{mM})$ in buffer K. Pure fractions of MBP-RECQ4-HIS were concentrated using VivaSpin-2 (GE Healthcare).

For GST proteins (GST and GST-MCM10) $E$. Coli cells were re-suspended in GST buffer $(20 \mathrm{mM}$ HEPES pH 7.5, $200 \mathrm{mM} \mathrm{KCl,} \mathrm{10 \%} \mathrm{glycerol,} 2 \mathrm{mM}$ $\beta$-mercaptoethanol, $1 \mathrm{mM}$ EDTA) supplemented with protease inhibitors (Roche) and lysed by addition of sodium lauroyl sarcosinate to final concentration of $0.8 \%$ for $10 \mathrm{~min}$ at $4^{\circ} \mathrm{C}$ on a rotating wheel. The lysate was then gently sonicated to shear genomic DNA and Triton X-100 was added to final concentration of $0.9 \%$ to reduce protein-protein interactions. The lysate was rotated for $5 \mathrm{~min}$ at $4^{\circ} \mathrm{C}$, before insoluble material was 
pelleted at $21000 \mathrm{~g}$ for $15 \mathrm{~min}$ at $4^{\circ} \mathrm{C}$. The cleared lysate was then diluted with GST buffer in 1:1 ratio to reduce detergent concentration and mixed with GSH beads. Binding of GST-proteins was performed for $30 \mathrm{~min}$ at $4^{\circ} \mathrm{C}$ on a rotating wheel. Resin was then washed extensively with GST buffer containing $0.5 \%$ Triton X-100. For GST pull-downs appropriate amount of beads containing GST or GST-MCM10 (equal microgram amounts of the GST protein) was taken for the assay. For peptide array GSTMCM10 was eluted with GST buffer ( $\mathrm{pH}$ 8.5) containing $30 \mathrm{mM}$ reduced glutathione.

\section{Surface plasmon resonance}

Surface Plasmon resonance was performed using a BIAcore T100 (GE Healthcare) instrument at $25^{\circ} \mathrm{C}$. GST MCM10 (30-50 $\mu \mathrm{g} / \mathrm{ml})$ was immobilized to a level of 500 response units using amine-coupling chemistry onto a CM3 chip. Two different flow rates ( 30 and $60 \mu \mathrm{l} /$ min) were used to study the interaction with the analyte (RECQ4) interaction. HBS buffer (10 mM HEPES, $\mathrm{pH}$ 7.4, $150 \mathrm{mM} \mathrm{NaCl}, 0.5 \mathrm{mM}$ TCEP, $0.05 \%$ Tween20) was used for dissociation. The sensograms were globally analyzed with the BIACORE T200 evaluation software (Biacore AB).

\section{Pull-down assays}

For pull-down of YFP-tagged proteins, U2OS cells $\left(8 \times 10^{6}\right)$ expressing YFP-RECQ4 variants were lysed in pull-down buffer $(10 \mathrm{mM}$ Tris $\mathrm{pH} 7.5,200 \mathrm{mM} \mathrm{KCl}$, $10 \%$ glycerol, $2 \mathrm{mM} \mathrm{MgCl} 2,0.5 \mathrm{mM}$ DTT, $0.5 \%$ NP40) supplemented with protease, phosphatase inhibitors (Roche) and benzonase (250 U/ml; Sigma) for $1 \mathrm{~h}$ at $4^{\circ} \mathrm{C}$ on a rotating wheel. Lysates were then gently sonicated to shear cell debris and insoluble material was spun at $21,000 \mathrm{~g}$ for $15 \mathrm{~min}$ at $4^{\circ} \mathrm{C}$. Protein concentration was then determined using BCA assay (Thermo Scientific) and approximately 1-2 mg of total cell extract was mixed with previously prepared GFP-Trap beads (Chromotek). Briefly, $30 \mu \mathrm{l}$ of GFP-Trap beads were washed with pull-down buffer and blocked for $1 \mathrm{~h}$ with $3 \mathrm{mg} / \mathrm{ml}$ of BSA in the same buffer. Lysate-beads mixture was then incubated for $2 \mathrm{~h}$ at $4^{\circ} \mathrm{C}$ on a rotating wheel. Resin was then extensively washed with pull-down buffer, protein complexes eluted in Laemmli buffer for $10 \mathrm{~min}$ at $95^{\circ} \mathrm{C}$ and analyzed by immunoblotting.

For GST pull-downs, beads with bound GST and GST-MCM10 proteins (approximately $1 \mu \mathrm{g}$ of GST proteins) were incubated with purified recombinant HISRECQ4 (approximately $1 \mu \mathrm{g}$ ) or fragments of MBPRECQ4-HIS in YFP pull-down buffer for $1 \mathrm{~h}$ at $4^{\circ} \mathrm{C}$ on a rotating wheel. For pull-down of MCM10 interaction domains of RECQ4 as HIS-fusions, GST or GST-MCM10 containing beads were incubated with bacterial cell lysates expressing RECQ4 domains previously prepared as described in section Protein Purification. Beads were then extensively washed with YFP pull-down buffer, re-suspended in Leammli buffer. Bound proteins were eluted by boiling for $10 \mathrm{~min}$ at $95^{\circ} \mathrm{C}$ and analyzed by immunoblotting.

\section{Peptide array analysis}

A peptide array of RECQ4 1-340 with 10 amino acids per peptide and 5 or 9 amino acids overlap was purchased from Kinexus (Vancouver, Canada). The peptides were spotted onto a membrane, which was incubated in $100 \%$ methanol for $10 \mathrm{~min}$ at room temperature and then washed three times with Tris Buffered Saline (TBS) for $5 \mathrm{~min}$ at room temperature. The membrane was then incubated in blocking buffer (4\% skimmed milk, 5\% sucrose in TBS containing $0.05 \%$ Tween 20 (TBS-T)) for $2 \mathrm{~h}$ at room temperature. The membrane was washed once in TBS-T for $5 \mathrm{~min}$ at room temperature and then incubated with purified GST-MCM10 at $0.1 \mu \mathrm{g} / \mathrm{ml}$ in blocking buffer for $1 \mathrm{~h}$ at $4^{\circ} \mathrm{C}$, followed by three 5 min washes in TBS-T and O/N incubation with MCM10 antibodies at $4^{\circ} \mathrm{C}$. After three 5 min washes in TBS-T, the membrane was incubated with secondary antibodies, washed three times for 5 min at room temperature and the signal was developed using an ECL kit (Thermo Scientific) and X-ray film (GE Healthcare).

\section{Cell fractionation}

Approximately $10^{6}$ of U2OS transiently transfected cells were lysed in $70 \mu 1$ of pull-down buffer supplemented with protease and phosphatase inhibitors (Roche) for 10 min on ice. The cell lysate $(30 \mu \mathrm{l})$ was mixed with $30 \mu \mathrm{l}$ of pull-down buffer and $30 \mu 1$ of 3x Laemmli buffer (whole cell extract). Another $30 \mu 1$ of lysate was centrifuged at $15,000 \mathrm{~g}$ for $10 \mathrm{~min}$ at $4^{\circ} \mathrm{C}$, and the supernatant was mixed with $30 \mu \mathrm{l}$ of pull-down and $30 \mu 1$ of $3 x$ Laemmli buffer (soluble fraction). The residual pellet was washed once with $1 \mathrm{ml}$ of pull-down buffer, centrifuged again, and the pellet was re-suspended in $30 \mu 1$ of pull-down buffer. Chromatin-bound proteins were released by the addition of $30 \mu \mathrm{l}$ of pull-down buffer supplemented with benzonase $(250 \mathrm{U} / \mathrm{ml})$, incubated for $30 \mathrm{~min}$ at $4^{\circ} \mathrm{C}$ and mixed with $30 \mu 1$ of $3 x$ Leammli buffer (insoluble fraction). All samples were then boiled for $10 \mathrm{~min}$ at $95^{\circ} \mathrm{C}$ and analyzed by immunoblotting.

\section{Flow cytometry}

Approximately, $0.5-1 \times 10^{6}$ of DT40 cells were harvested by centrifugation and re-suspended in $0.25 \mathrm{ml}$ 
of PBS. $0.5 \mathrm{ml}$ of $-20^{\circ} \mathrm{C}$ absolute ethanol was then added drop-wise to the cells while gently vortexing. Cells were fixed for at least $30 \mathrm{~min}$, the ethanol was removed, and the cells were washed twice with PBS and incubated in pre-warmed RPMI 1640 medium at $37^{\circ} \mathrm{C}$ for $30 \mathrm{~min}$. After removal of the medium, the cell pellet was treated with RNase A at $100 \mu \mathrm{g} / \mathrm{ml}$ and propidium iodide at $40 \mu \mathrm{g} / \mathrm{ml}$ in PBS for $30 \mathrm{~min}$. Flow cytometry was performed using FACS Caliber instrument (Beckman-Coulter).

\section{DNA fiber analysis}

DT40 cells were treated with doxycyline at $1 \mu \mathrm{g} /$ $\mathrm{ml}$ for $96 \mathrm{~h}$ prior to DNA fibre isolation. All steps were taken to protect degradation of IdU (Sigma) and CldU (Sigma) by sunlight. Approximately, $7.5 \times 10^{5}$ cells in $1 \mathrm{ml}$ of medium were labelled with $25 \mathrm{mM}$ IdU for 20 min at $37^{\circ} \mathrm{C}$ followed by labelling with $250 \mathrm{mM} \mathrm{CldU}$ for $20 \mathrm{~min}$ at $37^{\circ} \mathrm{C}$. After labelling, cells were harvested by centrifugation at $1200 \mathrm{rpm}$ for $5 \mathrm{~min}$, and then resuspended in ice cold PBS buffer. The cells $(2 \mu \mathrm{l})$ were then spotted onto glass slide (Superfrost, Thermo Fisher Scientific) and after $\sim 5-7$ min cells were mixed with $7 \mu 1$ of lysis buffer (200 mM Tris-HCl, pH7.4, 50 mM EDTA, $0.5 \% \mathrm{SDS}$ ). Cells were left to lyse for additional $2 \mathrm{~min}$ and slides were then tilted at an angle of $15^{\circ}$. After the drop reached the bottom of the slide, preparations were air-dried and fixed with methanol:acetic acid (3:1) solution for 10 min and air-dried. Slides were then washed with water and the DNA was denatured in $2.5 \mathrm{M} \mathrm{HCl}$ for $1.5 \mathrm{~h}$, followed by $3 \mathrm{x}$ water and $3 \mathrm{x}$ PBS washes. Preparations were then incubated with anti-IdU and anti-CldU antibodies in total volume of $30 \mu \mathrm{l}$ in 5\% BSA for $1 \mathrm{~h}$ at room temperature. After 3 x PBS wash, slides were incubated with secondary antibodies in 5\% BSA for $1 \mathrm{~h}$ at room temperature, washed $3 \times$ PBS, mounted with Vectashield (Vectorlabs) and analyzed by microscopy.

\section{Authors' contributions}

MK designed, performed the experiments and helped to write the manuscript. HS purified MBP-RECQ4HIS proteins. GPP purified HIS-RECQ4, MCM10 and performed the surface plasmon resonance experiments. LK and WWS supervised the experiments of HS and GPP, respectively. IDH supervised MK and wrote the manuscript.

\section{ACKNOWLEDGMENTS}

We thank Dr. Yilun Liu for GST-MCM10 plasmid, Dr. Takemi Enomoto for chicken RECQ4 knockout cells, and Dr Claus Storgaard Sørensen for MCM7 antibodies. We also thank Drs Ying Liu and Hocine Mankouri for critical reading of the manuscript.

\section{CONFLICTS OF INTEREST}

The authors declare no conflicts of interest.

\section{GRANT SUPPORT}

This work was supported by grants to IDH from the Nordea Foundation, The Danish Medical Research Council and the Danish National Research Foundation, and by grants to LK from the Czech Science Foundation, and the European Regional Development Fund and Research Support Program (GAMU).

\section{REFERENCES}

1. Bell SP and Stillman B. ATP-dependent recognition of eukaryotic origins of DNA replication by a multiprotein complex. Nature. 1992; 357(6374):128-134.

2. Besnard E, Babled A, Lapasset L, Milhavet O, Parrinello H, Dantec C, Marin JM and Lemaitre JM. Unraveling cell type-specific and reprogrammable human replication origin signatures associated with G-quadruplex consensus motifs. Nature Structural \& Molecular Biology. 2012; 19(8):837844.

3. Valton AL, Hassan-Zadeh V, Lema I, Boggetto N, Alberti P, Saintome C, Riou JF and Prioleau MN. G4 motifs affect origin positioning and efficiency in two vertebrate replicators. The EMBO journal. 2014; 33(7):732-746.

4. Evrin C, Clarke P, Zech J, Lurz R, Sun J, Uhle S, Li H, Stillman B and Speck C. A double-hexameric MCM2-7 complex is loaded onto origin DNA during licensing of eukaryotic DNA replication. Proceedings of the National Academy of Sciences. 2009; 106(48):20240-20245.

5. Gambus A, Khoudoli GA, Jones RC and Blow JJ. MCM27 Form Double Hexamers at Licensed Origins in Xenopus Egg Extract. Journal of Biological Chemistry. 2011; 286(13):11855-11864.

6. Labib K. How do Cdc7 and cyclin-dependent kinases trigger the initiation of chromosome replication in eukaryotic cells? Genes \& Development. 2010; 24(12):1208-1219.

7. Bruck I and Kaplan DL. Conserved mechanism for coordinating replication fork helicase assembly with phosphorylation of the helicase. Proceedings of the National Academy of Sciences. 2015; 112(36):11223-11228.

8. Zegerman P and Diffley JFX. Phosphorylation of Sld2 and Sld3 by cyclin-dependent kinases promotes DNA replication in budding yeast. Nature. 2007; 445(7125):281285.

9. Fukuura M, Nagao K, Obuse C, Takahashi TS, Nakagawa $\mathrm{T}$ and Masukata H. CDK promotes interactions of Sld3 and Drc1 with Cut5 for initiation of DNA replication in fission yeast. Molecular biology of the cell. 2011; 22(14):26202633.

10. Boos D, Sanchez-Pulido L, Rappas M, Pearl LH, Oliver 
AW, Ponting CP and Diffley JF. Regulation of DNA replication through Sld3-Dpb11 interaction is conserved from yeast to humans. Current Biology. 2011; 21(13):11521157.

11. Kumagai A, Shevchenko A, Shevchenko A and Dunphy WG. Treslin Collaborates with TopBP1 in Triggering the Initiation of DNA Replication. Cell. 2010; 140(3):349-359.

12. Ilves I, Petojevic T, Pesavento JJ and Botchan MR. Activation of the MCM2-7 helicase by association with Cdc45 and GINS proteins. Molecular cell. 2010; 37(2):247258.

13. Pacek M, Tutter AV, Kubota Y, Takisawa H and Walter JC. Localization of MCM2-7, Cdc45, and GINS to the site of DNA unwinding during eukaryotic DNA replication. Molecular cell. 2006; 21(4):581-587.

14. Thu YM and Bielinsky AK. Enigmatic roles of Mcm10 in DNA replication. Trends in Biochemical Sciences. 2013; 38(4):184-194.

15. Sangrithi MN, Bernal JA, Madine M, Philpott A, Lee J, Dunphy WG and Venkitaraman AR. Initiation of DNA replication requires the RECQL4 protein mutated in Rothmund-Thomson syndrome. Cell. 2005; 121(6):887898.

16. Matsuno K, Kumano M, Kubota Y, Hashimoto Y and Takisawa H. The N-Terminal Noncatalytic Region of Xenopus RecQ4 Is Required for Chromatin Binding of DNA Polymerase $\alpha$ in the Initiation of DNA Replication. Molecular and cellular biology. 2006; 26(13):4843-4852.

17. Marino F, Vindigni A and Onesti S. Bioinformatic analysis of RecQ4 helicases reveals the presence of a RQC domain and a Zn knuckle. Biophysical Chemistry. 2013; 177178:34-39.

18. Larizza L, Magnani I and Roversi G. Rothmund-Thomson syndrome and RECQL4 defect: splitting and lumping. Cancer Letters. 2006; 232(1):107-120.

19. Jensen MB, Dunn CA, Keijzers G, Kulikowicz T, Rasmussen LJ, Croteau DL and Bohr VA. The helicase and ATPase activities of RECQL4 are compromised by mutations reported in three human patients. Aging (Albany NY). 2012; 4(11):790-802.

20. Croteau DL, Rossi ML, Canugovi C, Tian J, Sykora P, Ramamoorthy M, Wang ZM, Singh DK, Akbari M, Kasiviswanathan R, Copeland WC and Bohr VA. RECQL4 localizes to mitochondria and preserves mitochondrial DNA integrity. Aging Cell. 2012; 11(3):456-466.

21. Fan W and Luo J. RecQ4 facilitates UV light-induced DNA damage repair through interaction with nucleotide excision repair factor xeroderma pigmentosum group A (XPA). The Journal of biological chemistry. 2008; 283(43):2903729044.

22. Schurman SH, Hedayati M, Wang Z, Singh DK, Speina E, Zhang Y, Becker K, Macris M, Sung P, Wilson DM, 3rd, Croteau DL and Bohr VA. Direct and indirect roles of RECQL4 in modulating base excision repair capacity.
Human molecular genetics. 2009; 18(18):3470-3483.

23. Singh DK, Karmakar P, Aamann M, Schurman SH, May A, Croteau DL, Burks L, Plon SE and Bohr VA. The involvement of human RECQL4 in DNA double-strand break repair. Aging Cell. 2010; 9(3):358-371.

24. Kohzaki M, Chiourea M, Versini G, Adachi N, Takeda $\mathrm{S}$, Gagos S and Halazonetis TD. The helicase domain and C-terminus of human RecQL4 facilitate replication elongation on DNA templates damaged by ionizing radiation. Carcinogenesis. 2012; 33(6):1203-1210.

25. Homesley L, Lei M, Kawasaki Y, Sawyer S, Christensen $\mathrm{T}$ and Tye BK. Mcm10 and the MCM2-7 complex interact to initiate DNA synthesis and to release replication factors from origins. Genes \& Development. 2000; 14(8):913-926.

26. Groocock LM, Prudden J, Perry JJ and Boddy MN. The RecQ4 orthologue Hrq1 is critical for DNA interstrand cross-link repair and genome stability in fission yeast. Molecular and cellular biology. 2012; 32(2):276-287.

27. Choi DH, Lee R, Kwon SH and Bae SH. Hrq1 functions independently of Sgs1 to preserve genome integrity in Saccharomyces cerevisiae. The Journal of Microbiology. 2013; 51(1):105-112.

28. Choi DH, Min MH, Kim MJ, Lee R, Kwon SH and Bae $\mathrm{SH}$. Hrq1 facilitates nucleotide excision repair of DNA damage induced by 4-nitroquinoline-1-oxide and cisplatin in Saccharomyces cerevisiae. The Journal of Microbiology. 2014; 52(4):292-298.

29. Ghosh AK, Rossi ML, Singh DK, Dunn C, Ramamoorthy M, Croteau DL, Liu Y and Bohr VA. RECQL4, the protein mutated in Rothmund-Thomson syndrome, functions in telomere maintenance. The Journal of biological chemistry. 2012; 287(1):196-209.

30. Bochman ML, Paeschke K, Chan A and Zakian VA. Hrq1, a homolog of the human RecQ4 helicase, acts catalytically and structurally to promote genome integrity. Cell reports. 2014; 6(2):346-356.

31. Abe T, Yoshimura A, Hosono Y, Tada S, Seki M and Enomoto T. The N-terminal region of RECQL4 lacking the helicase domain is both essential and sufficient for the viability of vertebrate cells. Role of the $\mathrm{N}$-terminal region of RECQL4 in cells. Biochimica et Biophysica Acta. 2011; 1813(3):473-479.

32. Xu X, Rochette PJ, Feyissa EA, Su TV and Liu Y. MCM10 mediates RECQ4 association with MCM2-7 helicase complex during DNA replication. The EMBO journal. 2009; 28(19):3005-3014.

33. Xu Y, Lei Z, Huang H, Dui W, Liang X, Ma J and Jiao R. dRecQ4 is required for DNA synthesis and essential for cell proliferation in Drosophila. PLoS One. 2009; 4(7):e6107.

34. Xu X and Liu Y. Dual DNA unwinding activities of the Rothmund-Thomson syndrome protein, RECQ4. The EMBO journal. 2009; 28(5):568-577.

35. Thangavel S, Mendoza-Maldonado R, Tissino E, Sidorova JM, Yin J, Wang W, Monnat RJ, Jr., Falaschi A and 
Vindigni A. Human RECQ1 and RECQ4 helicases play distinct roles in DNA replication initiation. Molecular and cellular biology. 2010; 30(6):1382-1396.

36. Collart C, Allen GE, Bradshaw CR, Smith JC and Zegerman P. Titration of Four Replication Factors Is Essential for the Xenopus laevis Midblastula Transition. Science. 2013.

37. Keller H, Kiosze K, Sachsenweger J, Haumann S, Ohlenschlager O, Nuutinen T, Syvaoja JE, Gorlach M, Grosse F and Pospiech H. The intrinsically disordered amino-terminal region of human RecQL4: multiple DNAbinding domains confer annealing, strand exchange and G4 DNA binding. Nucleic acids research. 2014.

38. Sedlackova H, Cechova B, Mlcouskova J and Krejci L. RECQ4 selectively recognizes Holliday junctions. DNA Repair (Amst). 2015; 30:80-89.

39. Ohlenschlager O, Kuhnert A, Schneider A, Haumann S, Bellstedt P, Keller H, Saluz HP, Hortschansky P, Hanel F, Grosse F, Gorlach M and Pospiech H. The N-terminus of the human RecQL4 helicase is a homeodomain-like DNA interaction motif. Nucleic acids research. 2012.

40. Gambus A, van Deursen F, Polychronopoulos D, Foltman M, Jones RC, Edmondson RD, Calzada A and Labib K. A key role for Ctf4 in coupling the MCM2-7 helicase to DNA polymerase alpha within the eukaryotic replisome. The EMBO journal. 2009; 28(19):2992-3004.

41. Im JS, Park SY, Cho WH, Bae SH, Hurwitz J and Lee JK. RecQL4 is required for the association of Mcm10 and Ctf4 with replication origins in human cells. Cell Cycle. 2015; 14(7):1001-1009.

42. Nasmyth K and Nurse P. Cell division cycle mutants altered in DNA replication and mitosis in the fission yeast Schizosaccharomyces pombe. Molecular Genetics and Genomics. 1981; 182(1):119-124.

43. Dumas LB, Lussky JP, McFarland EJ and Shampay J. New temperature-sensitive mutants of Saccharomyces cerevisiae affecting DNA replication. Molecular Genetics and Genomics. 1982; 187(1):42-46.

44. Cook CR, Kung G, Peterson FC, Volkman BF and Lei M. A novel zinc finger is required for Mcm10 homocomplex assembly. The Journal of biological chemistry. 2003; 278(38):36051-36058.

45. Hart EA, Bryant JA, Moore K and Aves SJ. Fission yeast $\mathrm{Cdc} 23$ interactions with DNA replication initiation proteins. Current Genetics. 2002; 41(5):342-348.

46. Kanke M, Kodama Y, Takahashi TS, Nakagawa T and Masukata H. Mcm10 plays an essential role in origin DNA unwinding after loading of the CMG components. The EMBO journal. 2012; 31(9):2182-2194.

47. Heller Ryan C, Kang S, Lam Wendy M, Chen S, Chan Clara S and Bell Stephen P. Eukaryotic Origin-Dependent DNA Replication In Vitro Reveals Sequential Action of DDK and S-CDK Kinases. Cell. 2011; 146(1):80-91.

48. Taylor M, Moore K, Murray J, Aves SJ and Price C. Mcm10 interacts with $\operatorname{Rad} 4 / \mathrm{Cut5}(\mathrm{TopBP} 1)$ and its association with origins of DNA replication is dependent on Rad4/ Cut5(TopBP1). DNA Repair (Amst). 2011; 10(11):11541163.

49. Yeeles JT, Deegan TD, Janska A, Early A and Diffley JF. Regulated eukaryotic DNA replication origin firing with purified proteins. Nature. 2015; 519(7544):431-435.

50. Ichikawa K, Noda T and Furuichi Y. Preparation of the gene targeted knockout mice for human premature aging diseases, Werner syndrome, and Rothmund-Thomson syndrome caused by the mutation of DNA helicases. Folia Pharmacologica Japonica. 2002; 119(4):219-226.

51. Capp C, Wu J and Hsieh TS. Drosophila RecQ4 has a 3'-5' DNA helicase activity that is essential for viability. The Journal of biological chemistry. 2009; 284(45):3084530852.

52. Yekezare M, Gomez-Gonzalez B and Diffley JF. Controlling DNA replication origins in response to DNA damage - inhibit globally, activate locally. Journal of Cell Science. 2013; 126(Pt 6):1297-1306.

53. Im JS, Ki SH, Farina A, Jung DS, Hurwitz J and Lee JK. Assembly of the Cdc45-Mcm2-7-GINS complex in human cells requires the Ctf4/And-1, RecQL4, and Mcm10 proteins. Proceedings of the National Academy of Sciences. 2009; 106(37):15628-15632.

54. Bruck I, Kanter DM and Kaplan DL. Enabling association of the GINS protein tetramer with the mini chromosome maintenance (Mcm)2-7 protein complex by phosphorylated Sld2 protein and single-stranded origin DNA. The Journal of biological chemistry. 2011; 286(42):36414-36426.

55. van Deursen F, Sengupta S, De Piccoli G, Sanchez-Diaz A and Labib K. Mcm10 associates with the loaded DNA helicase at replication origins and defines a novel step in its activation. The EMBO journal. 2012; 31(9):2195-2206.

56. Smeets MF, DeLuca E, Wall M, Quach JM, Chalk AM, Deans AJ, Heierhorst J, Purton LE, Izon DJ and Walkley CR. The Rothmund-Thomson syndrome helicase RECQL4 is essential for hematopoiesis. The Journal of Clinical Investigations. 2014; 124(8):3551-3565.

57. Sørensen CS, Lukas C, Kramer ER, Peters J-M, Bartek J and Lukas J. Nonperiodic Activity of the Human AnaphasePromoting Complex-Cdh1 Ubiquitin Ligase Results in Continuous DNA Synthesis Uncoupled from Mitosis. Molecular and cellular biology. 2000; 20(20):7613-7623.

58. Rossi ML, Ghosh AK, Kulikowicz T, Croteau DL and Bohr VA. Conserved helicase domain of human RecQ4 is required for strand annealing-independent DNA unwinding. DNA Repair (Amst). 2010; 9(7):796-804. 